Research Article

\title{
Influence of the Force Arm on the Flexural Performance of Prestressed Glulam Beams
}

\author{
Lidan Mei $\mathbb{D}^{D}$, Nan Guo $(\mathbb{D}$, Hongliang Zuo, Ling Li, and Guodong Li \\ College of Civil Engineering, Northeast Forestry University, Harbin 150040, China \\ Correspondence should be addressed to Nan Guo; snowguonan@163.com
}

Received 16 March 2020; Revised 5 November 2020; Accepted 30 December 2020; Published 15 January 2021

Academic Editor: Pier Paolo Rossi

Copyright (c) 2021 Lidan Mei et al. This is an open access article distributed under the Creative Commons Attribution License, which permits unrestricted use, distribution, and reproduction in any medium, provided the original work is properly cited.

\begin{abstract}
In recent years, extensive attention has been drawn to prefabricated buildings, particularly wood construction. Glulam beams are the major supporting components of modern wood buildings. Since the force arm is the most critical indicator to evaluate the resistance moment of the glulam beam string structure, it is necessary to further study the influence of the force arm on the mechanical properties of the glulam beam string structure. We tested the flexural performance of 15 prestressed glulam beams, which were divided into two groups (A and B) to, respectively, research the influences of the string arm and the end arm on the bearing capacity, failure mode, stress distribution, and deformation performance of glulam beams. The results showed that when the height of the end arm remained constant and the string arm increased from $90 \mathrm{~mm}$ to $130 \mathrm{~mm}$ and $170 \mathrm{~mm}$, the bearing capacity of the beam increased by $6.77 \%$ and $17.22 \%$, respectively. Moreover, as the depth of the compression zone of the glued timber beam gradually increased, the failure mode of the beam changed from the brittle tension failure of the beam bottom to the ductile compression failure of the beam top. When the height of the string arm remained constant and the end arm increased from $10 \mathrm{~mm}$ to $30 \mathrm{~mm}$ and $50 \mathrm{~mm}$, the bearing capacity of the beam increased by $4.27 \%$ and $8.13 \%$, respectively. The beam had no significant change in the failure mode, while it could bear the stress more uniformly. Based on the experimental results and principles of equilibrium, moment equilibrium, and similar triangle, we calculated the ultimate bearing capacity of the glulam beam and proposed a design method for durable wood structures.
\end{abstract}

\section{Introduction}

In recent years, China has introduced many policies on building structures, such as the National Medium and LongTerm Science and Technological Development Program (2006-2020) and Several Opinions of the State Council of the Central Committee of the Communist Party of China on Further Enhancing Administration of Urban Planning and Construction. Wood construction, as an important type of prefabricated buildings, has been given priority in terms of research and development. The materials to build modern wood constructions are diverse, including glued laminated timber, carbonized timber, composites, and cross-laminated timber [1-5]. In particular, the most well-known and widely used material is glued laminated timber. Due to its advantages such as scattered defects and reasonable bearing capacity, it is often used as the major supporting component of the structure.

Current research on glulam beams is mainly focused on the flexural properties of ordinary and prestressed glulam beams [6-14]. De Luca and Marano [15] assessed the flexural properties of unreinforced, reinforced, and prestressed glulam beams. The test results indicated that the mechanical strength, bearing capacity, and stiffness of prestressed reinforced beams were effectively improved. Yang et al. [16] reinforced glulam beams by carbon fiber-reinforced polymer bar and proposed a theoretical model for predicting the flexural bearing capacity of the reinforced beam, which was verified by experimental data. Zhang et al. [17] found that the short-term flexural properties of glulam beams is less affected by the prestressing tendon line type, while the ultimate bearing capacity of prestressed glulam beams can be 
effectively improved by increasing the tension control stress, but the improvement of flexural stiffness is not significant.

At present, the influence of force arm on the flexural properties of glulam beams has not been intensively studied; thus, studies on the force arm mainly address the effect of force arm on the mechanical performance of the materials, such as Engineered Cementitious Composite Reinforced Concrete (ECC-RC) and concrete [18]. Gui et al. [19] analyzed the factors influencing the flexural properties of ECC$\mathrm{RC}$ composite beams. In the comparative test of the three kinds of material composite beam, the results revealed that the increase of the internal force arm helps to resist the external bending moment. Peng et al. [20] conducted mechanical experiments on corroded light-round reinforced concrete flexural members, and the results showed that increasing the internal force arm can make full use of the material strength and improve the resistance to external bending moment. Li et al. [21] used SAP software to establish the analysis model of wood beam and explored the influence of force arm on the bearing capacity and deformation capacity of the beam by changing the arm size.

In this work, we studied the influences of the string arm and the end arm on the flexural performance of the beam. We divided 15 glulam beams into two groups: A and B. For beams in group $\mathrm{A}$, the anchoring position of the end of the prestressed steel wire remained the same, while the height of the string varied. For group B, the height of the string of the prestressed steel was constant, while the anchoring position of the end changed. Groups A and B were tested to study the impacts of the string arm and the end arm on the bearing capacity, failure mode, stress distribution, and deformation performance of the glulam beam.

\section{Materials and Methods}

2.1. Specimen Design. The prestressed glulam beam used in this study is a steel-timber composite and is composed of glued laminated timber, high-strength steel wire, and string anchor device (Figure 1). The glued laminated timber with dimensions $3150 \mathrm{~mm}$ (length) $\times 100 \mathrm{~mm}$ (width) $\times 100 \mathrm{~mm}$ (height) was glued by five layers of $20 \mathrm{~mm}$ thick spruce-pinefir (SPF) planks. Low-relaxation prestressed steel wire with a compressive strength of $1570 \mathrm{MPa}$ and a diameter of $7 \mathrm{~mm}$ was used.

The force arm was divided into the end arm and string arm to explore the influence of the size of the force arm on the flexural performance of the beam. Based on these two parameters, the test beams were divided into two groups, A and $\mathrm{B}$ (Table 1). For group A, the anchoring position of the end was kept the same, while the height of the string changed. For group B, the position of the string remained the same, while the anchoring position of the end varied. Groups A and B were tested to study the influences of the end arm and string arm on the bearing capacity, failure mode, and deformation performance of the glulam beam.

2.2. Measurement Layout and Loading Mechanism. The distribution beams were tested under two-point loading to form pure bending in the midspan. To measure the strain state of the glued laminated timber and steel wire, the gauge with a size of $100 \mathrm{~mm} \times 3 \mathrm{~mm}$ was pasted at the three dividing points of the beam side and the top and bottom of the midspan, and the gauge with a size of $20 \mathrm{~mm} \times 3 \mathrm{~mm}$ was pasted on the steel wire. To obtain the deflection value of the beam, a displacement meter with a measuring range of $100 \mathrm{~mm}$ was placed at the support, and a displacement meter with a measuring range of $150 \mathrm{~mm}$ was set in the midspan. The measuring point layout is shown in Figure 2.

The loading process of the prestressed glulam beam can be divided into the prestressing stage and external loading stage. When the prestress is applied, the steel wire is under tension and the prestress is transferred to the glued laminated timber through the anchor end. In this process, the glued laminated bears the axial compression bending moment, as shown in Figure 3.

During the prestressing stage, through the lateral tensioning wire, the glued laminated timber is subjected to axial compression $F$ and bending moment $M$ at the beam-end and is subjected to concentrated force $F^{\prime}$ generated by the screw top at the lower three dividing points. The bending moment formed by the prestress is shown in Figure 4(a). In the case of applying only an external load, the compression $P$ generated by the top of the Jack is divided into two forces through the distribution beam, and the concentrated force $P / 2$ is formed at the upper three dividing points. The bending moment formed by the external load is shown in Figure 4(b). Thus, the bending moment generated during the loading stage can be drawn as the superposition of the above figures, as shown in Figure 4(c).

As can be seen from Figure 4, the beam resists the bending moment caused by the external load through the force couple of tension and compression provided by the material. Therefore, by changing the size of the string arm, the material properties of steel wire and glued laminated timber can be fully used to help improve the bending resistance of glulam beams. Furthermore, the larger the $x$ value from the anchoring position of the beam-end to the centroid of the glued laminated timber, the larger the $M$ value formed at the beam-end, and thereby the smaller the positive bending moment formed by the superposition of the bending moment. According to this analysis, the end arm directly affects the bending moment distribution of the beam, which, in turn, affects the ultimate load and failure mode of the beam. Therefore, it is necessary to study the influence of the end arm on the glulam beam.

\subsection{Principles for Determining Failure and Ultimate Loads.} According to the failure determination of wood components based on the Wood Construction Design Standard (GB/T50329-2012), as well as the failure determination of the reinforced concrete components based on the Test Method Standard of Concrete Structures (GB50152-2012), combined with the actual situation of this test, the failure signs of the glulam beams can be summarized as the following three situations. When one of them appears in the test, it can be determined that the beam failed: 


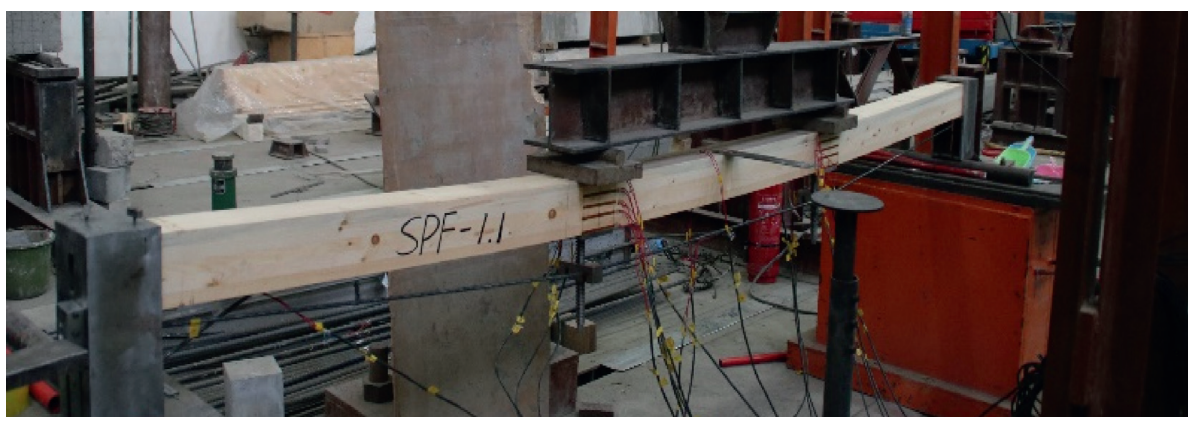

Figure 1: Prestressed glulam beam.

TABLE 1: Basic parameters for test components.

\begin{tabular}{|c|c|c|c|c|c|c|}
\hline Group & Beam no. & Prestress value $\left(\mathrm{N} / \mathrm{mm}^{2}\right)$ & Number of steel wires & End $^{1}(\mathrm{~mm})$ & String $^{2}(\mathrm{~mm})$ & Number of beams \\
\hline \multirow{3}{*}{ A } & SPF-1.1 & 99 & 2 & 10 & 90 & 3 \\
\hline & SPF $-1.2^{3}$ & 99 & 2 & 10 & 130 & 3 \\
\hline & SPF-1.3 & 99 & 2 & 10 & 170 & 3 \\
\hline \multirow{3}{*}{ B } & SPF-1.2 $2^{4}$ & 99 & 2 & 10 & 130 & 3 \\
\hline & SPF-2.2 & 99 & 2 & 30 & 130 & 3 \\
\hline & SPF-3.2 & 99 & 2 & 50 & 130 & 3 \\
\hline
\end{tabular}

${ }^{1}$ Distance from the reinforcement at the end to the bottom of the glued laminated timber; ${ }^{2}$ distance from the reinforcement at the string to the bottom of the glued laminated timber; ${ }^{3,4}$ test under the same condition with the same test data.

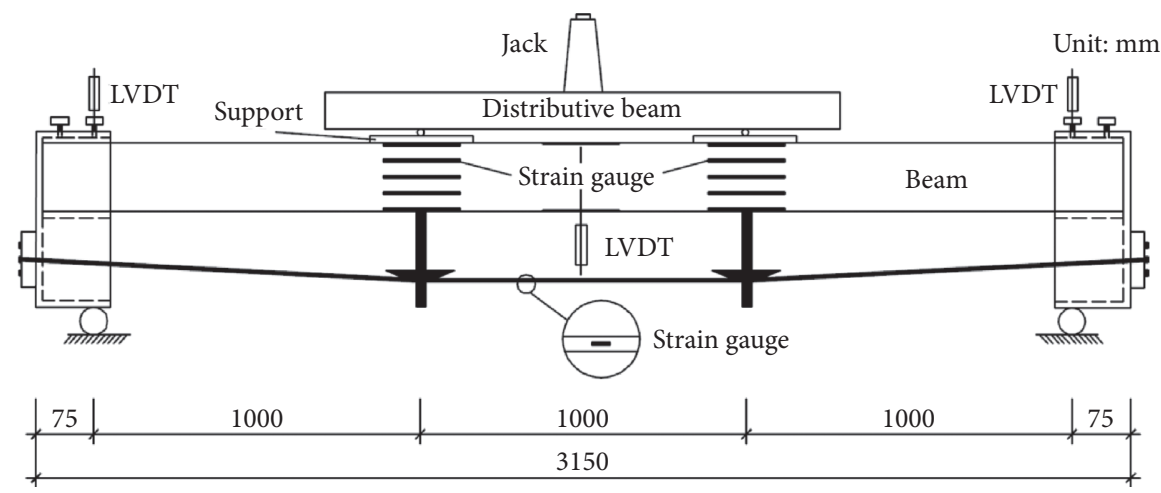

FIGURE 2: Loading mechanism of the prestressed glulam beam and layout of the strain gauge.
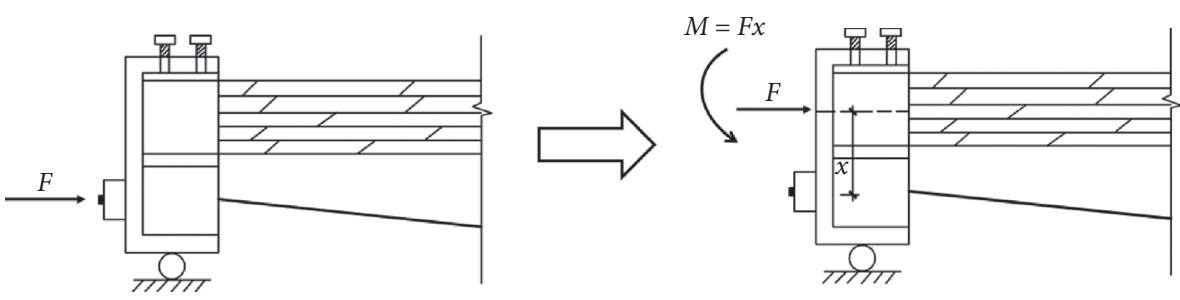

FIGURE 3: Interaction between steel wire and glued laminated timber.

(1) The tensile strain of the prestressed steel wire reaches 0.01 .

(2) Apparent cracks appear in the tension zone of the glulam beam, or significant wrinkles occur in the compression zone of the glulam beam. In addition, the load-deflection curve decreases with loading; that is, the load drops below $85 \%$ of the peak load.

(3) The prestressed steel wire is broken, or the anchor device at the beam-end fails. 


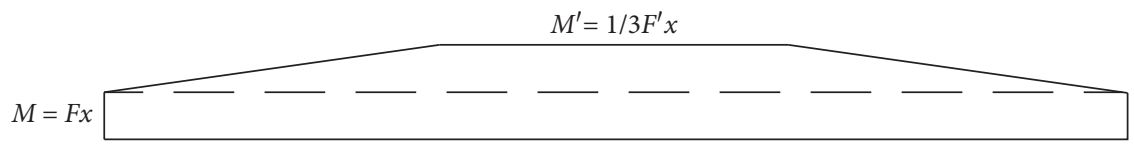

(a)

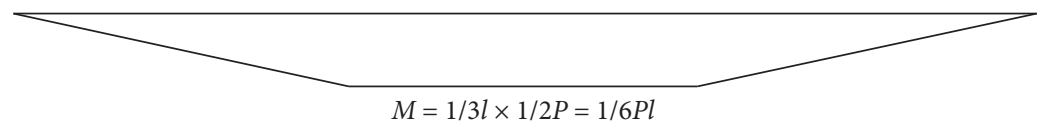

(b)

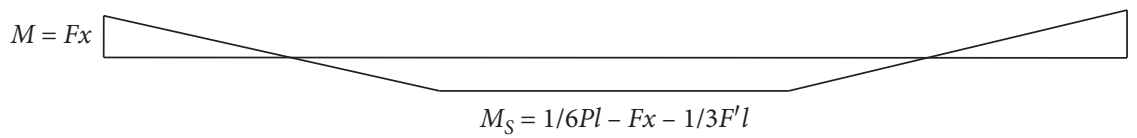

(c)

Figure 4: Bending moment of the glued laminated timber. (a) Bending moment during the prestressing stage. (b) Bending moment during the external loading stage. (c) Superposition of the bending moment during the loading process.

In the step loading test, the measured values of the ultimate load are determined according to the following principles:

(1) When a failure sign appears during the loading process, the load value of the previous grade is taken as the measured value of the ultimate load in the test.

(2) When the failure sign appears during the sustained loading process, the average value of the load of this grade and the load of the previous grade is taken as the measured value of the ultimate load in the test.

(3) When the failure sign appears after the sustained loading is completed, the load value of this grade is taken as the measured value of the ultimate load in the test.

\section{Results and Discussion}

3.1. Failure Mode. Among the three beams under the same working conditions, a representative beam is chosen to describe the test phenomenon.

For SPF-1.1, due to the short distance between the wire and the beam bottom and small internal force arm that is used to resist the bending moment caused by the external load, the tension in the wire and the compression in the glulam beam (the resultant force of the compressive stress at the top and the tensile stress at the bottom) are relatively large. The failure of the glued laminated timber is mainly due to bending; the larger the tensile stress at the bottom, the larger the deformation is. The weak part of the beam bottom (such as the knot) cracked first, and when the crack propagated to a certain level, the bottom laminate suddenly broke, as shown in Figure 5(a). For SPF-1.2, the steel wire is at a certain distance from the bottom of the beam, increasing the force couple of the tension generated by the glued laminated timber and steel wire compared to SPF-1.1. The tensile stress at the bottom of the glued laminated timber is reduced, and the glued laminated timber is more uniformly stressed. After the bottom laminate is damaged due to tension, the stress extends to the upper layer, causing a lateral tear to the upper laminate, as shown in Figure 5(b). For SPF-1.3, as the distance between the steel wire and the bottom of the beam is further increased, the glued laminated timber and steel wire produce a relatively large force couple of tension and compression, and the neutral axis is further reduced. Part of the glued laminated timber is mainly subjected to compression; with the increasing load, wrinkles gradually appear at the top of the beam, resulting in ductile compression failure, as shown in Figure 5(c). For SPF-2.2, due to the long distance between the steel wire and the beam centroid and increased $M$ value of the beam-end compared with SPF1.2, the beam is stressed more uniformly. Although the end arm can change the bending moment distribution of the whole beam, it has less impact on the stress distribution of the glued laminated timber in midspan; thus, the beam bottom is also damaged by tension, as shown in Figure 5(d). With regard to SPF3.2, if the steel wire is far away from the beam centroid, the $M$ value of the beam-end formed by the wire is relatively large. The end of the glued laminated timber in the boot-shaped anchor device would crack, leading to the redistribution of the internal force of the glued laminated timber and tension failure of the beam bottom, as shown in Figure 5(e).

Thus, when the force arm is relatively small, the bottom laminate of the prestressed glulam beams breaks when subjected to tension. When the force arm reaches a moderate value, the bottom of the beam is subjected to tension failure. On the other hand, the top of the beam is subjected to compression failure when the force arm is relatively large. The failure modes and the corresponding ultimate loads are described in Table 2.

3.2. Ultimate Load, Deflection, and Failure Modes. The ultimate load of test beams and the corresponding deflection values and failure modes are summarized in Table 2.

As the SPF-1.2 (1) and SPF-1.3 (1) are subjected to relatively large prestresses, the strain value generated at the top of the beam exceeds the design value of strength. Thus, the obtained data do not follow a common rule and thereby are not taken into consideration. 


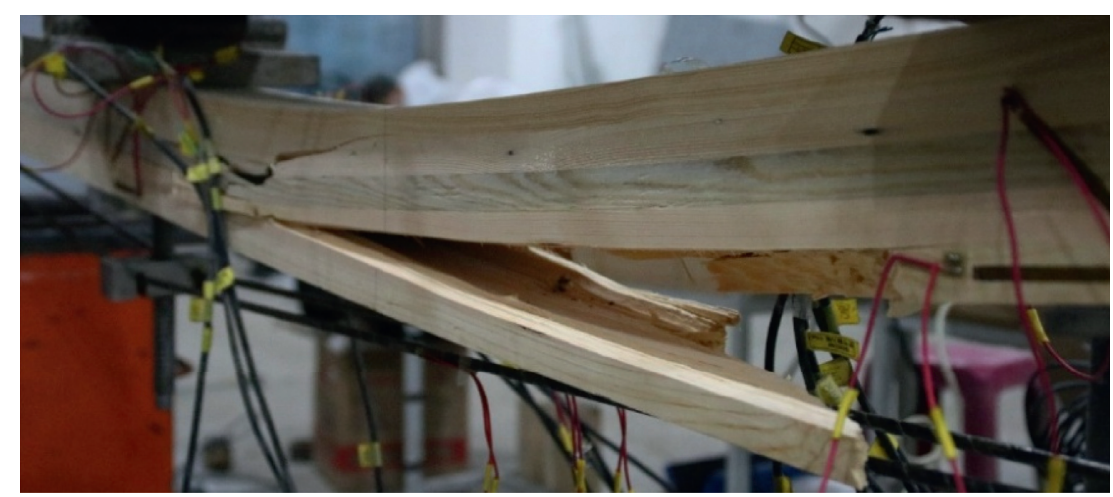

(a)

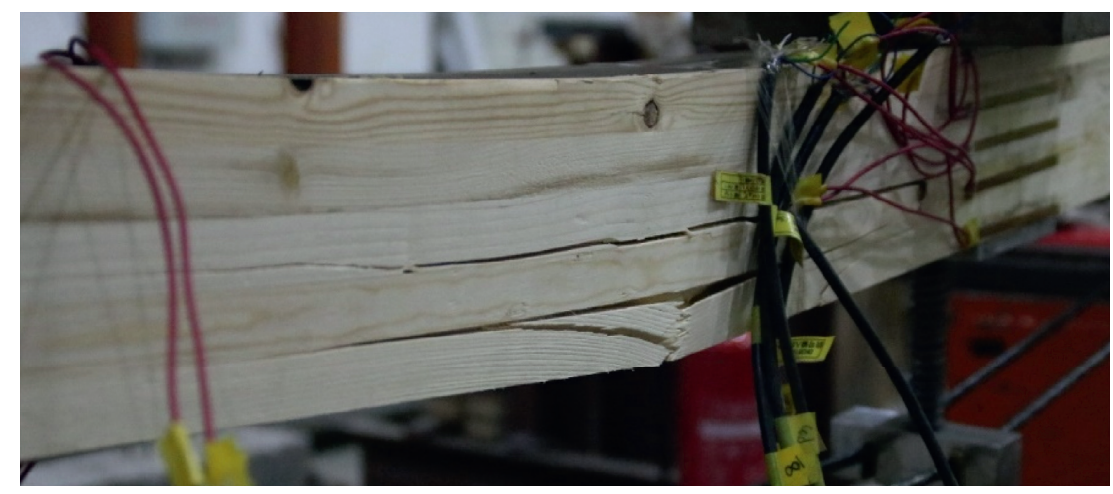

(b)

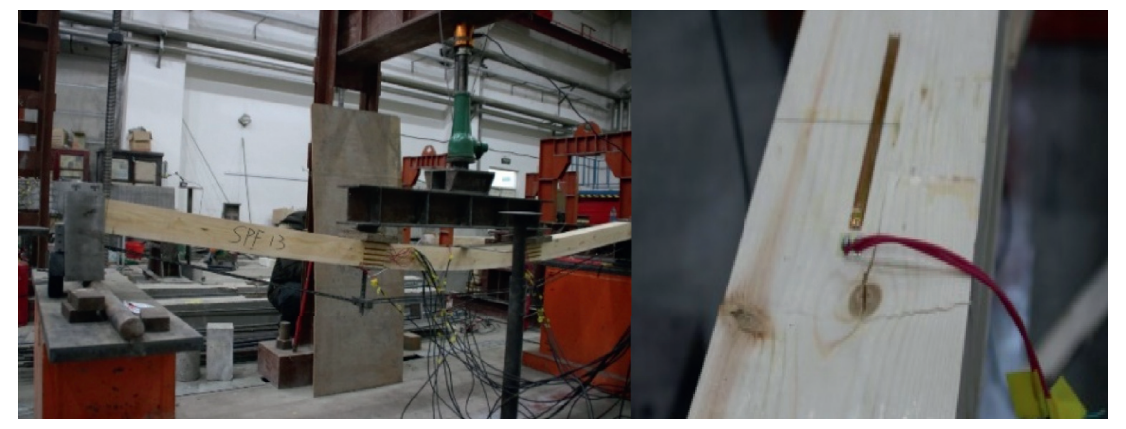

(c)

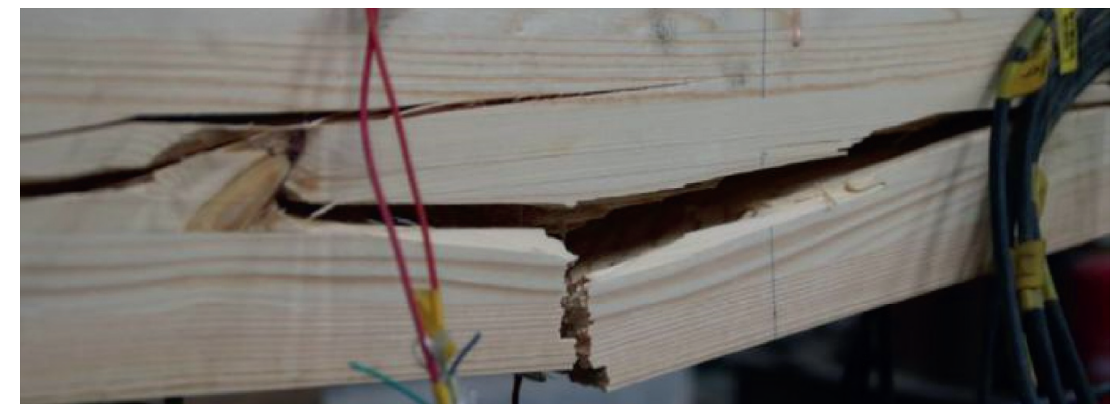

(d)

FIgURE 5: Continued. 


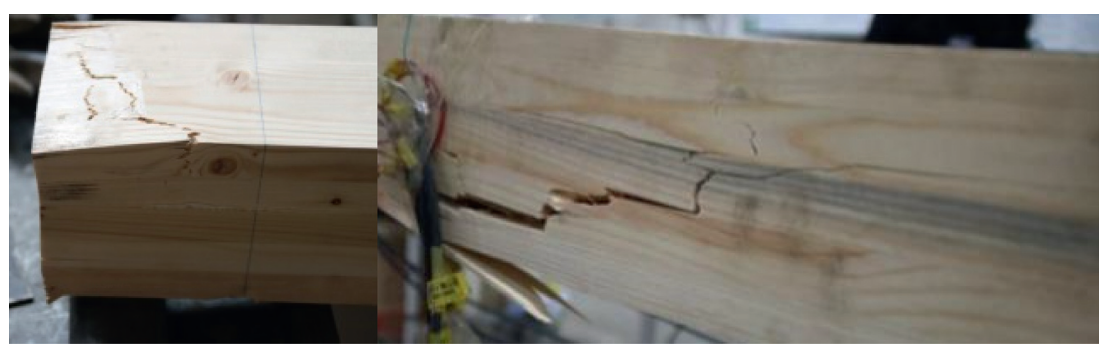

(e)

FIGURE 5: Failure modes of test beams. (a) Tension failure of the bottom laminate of SPF-1.1. (b) Tension failure of the beam bottom of SPF1.2. (c) Compression failure of the beam top of SPF-1.3. (d) Tension failure of the bottom of SPF-2.2. (e) Tension failure caused by the crack of the end of SPF-3.2.

TABLe 2: Ultimate load, deflection, and failure mode of test beams.

\begin{tabular}{|c|c|c|c|c|c|c|}
\hline \multirow{2}{*}{ Group } & \multirow{2}{*}{ Beam no. } & \multicolumn{2}{|c|}{ Ultimate load (kN) } & \multicolumn{2}{|c|}{ Deflection (mm) } & \multirow{2}{*}{ Failure mode } \\
\hline & & Test value & Average value & Test value & Average value & \\
\hline \multirow{3}{*}{ SPF-1.1 } & SPF-1.1 (1) & 22.40 & \multirow{3}{*}{22.59} & 57.57 & \multirow{3}{*}{58.34} & Tension failure of steel bar \\
\hline & SPF-1.1 (2) & 20.99 & & 59.11 & & Tension failure of the lowermost laminate \\
\hline & SPF-1.1 (3) & 24.39 & & 111.55 & & Breakage of the lowermost laminate \\
\hline \multirow{3}{*}{ SPF-1.2 } & SPF-1.2 (1) & - & \multirow{3}{*}{24.12} & - & \multirow{3}{*}{81.07} & - \\
\hline & SPF-1.2 (2) & 23.16 & & 75.84 & & Tension failure of the beam bottom \\
\hline & SPF-1.2 (3) & 25.08 & & 86.29 & & Tension failure of the beam bottom \\
\hline \multirow{3}{*}{ SPF-1.3 } & SPF-1.3 (1) & - & \multirow{3}{*}{26.48} & - & \multirow{3}{*}{101.28} & - \\
\hline & SPF-1.3 (2) & 27.37 & & 99.43 & & Compression failure of the beam top \\
\hline & SPF-1.3 (3) & 25.59 & & 103.12 & & Ductile tension failure of the beam bottom \\
\hline \multirow{3}{*}{ SPF-2.2 } & SPF-2.2 (1) & 23.03 & \multirow{3}{*}{25.15} & 88.46 & \multirow{3}{*}{85.40} & - \\
\hline & SPF-2.2 (2) & 25.08 & & 83.79 & & Tension failure of the beam bottom \\
\hline & SPF-2.2 (3) & 27.33 & & 83.96 & & Tension failure of the beam bottom \\
\hline \multirow{3}{*}{ SPF-3.2 } & SPF-3.2 (1) & 26.58 & \multirow{3}{*}{26.08} & 76.27 & \multirow{3}{*}{83.23} & $\begin{array}{c}\text { Tension failure of the beam bottom due to the beam-end } \\
\text { breakage }\end{array}$ \\
\hline & SPF-3.2 (2) & 25.83 & & 105.21 & & $\begin{array}{c}\text { Tension failure of the beam bottom due to the beam-end } \\
\text { breakage }\end{array}$ \\
\hline & SPF-3.2 (3) & 25.83 & & 68.22 & & $\begin{array}{l}\text { Tension failure of the beam bottom due to the beam-end } \\
\text { breakage }\end{array}$ \\
\hline
\end{tabular}

Despite the great difference between timbers, the data obtained from the test beams confirm a common rule: when the prestress value and the number of steel wires in different beams are the same, the further the distance between the steel wire and the bottom of the beam at string, the greater the ultimate load value. Compared with SPF-1.1, the bearing capacity of SPF-1.2 and SPF-1.3 increased by $6.77 \%$ and $17.22 \%$, respectively; the failure mode of the beam also gradually changed from the brittle tension failure of the beam bottom to the ductile compression failure of the beam top. When the number of steel wires in different beams and the prestress value are the same, the larger the height of the end arm, the greater the ultimate load value. Compared with SPF-1.2, the bearing capacity of SPF-2.2 and SPF-3.2 increased by $4.27 \%$ and $8.13 \%$, respectively; the beam has no significant change in failure mode; however, the increase in the height of the end arm should be controlled reasonably to avoid the beam-end breakage.
3.3. Load-Deflection Curve. Among the three beams of each group under the same working conditions, a representative one was selected to show the load-deflection relationship curve. Also, the curves of different string arms and end arms were compared, as shown in Figures 6 and 7.

As shown in Figure 6, when the load is zero, the value of displacement is negative because the beam is reversely arched during the prestressing stage. As the load on the upper part of the beam increases, the displacement value changes from negative to zero, and the reverse arch disappears. As the load continues to increase, the deflection increases. With the increase of the height of the string arm, the ultimate bearing capacity and deformation capacity of the beam are greatly improved. When the beam enters the plastic stage, the stiffness of the beam with a large force arm decreases slowly because, under the same load grade, the deflection of the beam with a large arm is small, and the cracks develop slowly. 
Figure 7 shows that, at the initial stage of loading, the stress of the steel wire is small, and the stress and deformation of the beam with different heights of end arms are similar because the prestress applied to the beam is limited to ensure that the tensile stress on the top of the glued laminated timber does not exceed its tensile strength. With the increase of load, the stiffness of the beam with a smaller end arm decreases rapidly. In other words, under the same load, the smaller the force on the end arm, the more significant the beam cracks and the larger the deflection, because the smaller the end arm, the smaller the beam-end bending moment generated by the steel wire, making the glued laminated timber prone to crack.

3.4. Load-Strain Relationship. The relationship between load and strain for prestressed glulam beams is shown in Figures 8 and 9, in which (1) (5) represents the number of laminates. Besides, the negative $X$-axis indicates that the material is under compression; the positive $X$-axis indicates that the material is under tension; the $Y$-axis represents the load; and the different curves show the mechanical behavior of the laminate and wire at different heights.

Figure 8 shows that, at the initial stage of loading, the top of the beam is under tension, and the bottom of the beam is under compression. At the beginning of loading, the strains at the top and the bottom of the beam are gradually reduced. When the strain is reduced to 0 , compressive and tensile strains are, respectively, generated at the top and bottom of the beam. Then, as the loading continues, the compressive strain of the beam top and the tensile strain of the beam bottom gradually increase. The loads at the bottom of SPF1.1, SPF-1.2, and SPF-1.3 are 2.5, 5, and $7.5 \mathrm{kN}$, respectively, indicating that the larger the string force arm, the larger the corresponding external load of the beam bottom when subjected to tension.

During the tests of SPF-1.1 and SPF-1.2, the steel wire is in the elastic phase, the slope of the curve does not change, and the stress of the steel wire is not fully exerted. As for SPF1.3, the slope is significantly reduced at a later stage of loading, and the strength of the wire is fully utilized. The glued laminated timber is not in a full-section compression state because, to ensure that the tensile stress at the top of the glued laminated timber does not exceed its tensile strength, limited prestress was applied to the beam. Therefore, the increase of the string arm can increase the compression range of the full-section so that the beam is in a better state of stress.

As shown in Figure 9, when SPF-1.2 is damaged, two layers of laminates in the compression zone are damaged, whereas three layers of laminates in the compression zone are damaged when SPF-2.2 and SPF-3.2 are damaged. This result indicates that the larger the end arm, the higher the compression zone of the beam cross section before the failure, and the more significant the influence that the compressive strength of the glued laminated timber exerts. Therefore, the ultimate bearing capacity of the glulam beams increases with the increase of the end arm.

To further study the strain change at the bottom of the glued laminated timber, the load-strain curve of the fifth- layer laminate of the above test beams is measured and compared, as shown in Figures 10 and 11.

Figure 10 shows that the failure load values of SPF-1.1, SPF-1.2, and SPF-1.3 are $22.40 \mathrm{kN}, 25.08 \mathrm{kN}$, and $27.37 \mathrm{kN}$, respectively. The tension and compression load of the fifthlayer laminate reaches the critical values at loads of $2.72 \mathrm{kN}$, $6.26 \mathrm{kN}$, and $10.56 \mathrm{kN}$, respectively. That is, before reaching the critical values, the full-section of the beam is under compression, while after that, the lowermost laminate is under tension. Based on the ratio of the critical value of the tension and compression load to the failure load of the fifthlayer laminate, the test beams SPF-1.1, SPF-1.2, and SPF-1.3 are subjected to tension when reaching the corresponding ultimate loads of $12.10 \%, 24.96 \%$, and $38.58 \%$, respectively. With the increase of the height of the string arm, the beam is prone to full-section compression failure.

As can be seen from Figure 11, the failure load values of SPF-1.2, SPF-2.2, and SPF-3.2 are $23.16 \mathrm{kN}, 23.03 \mathrm{kN}$, and $26.58 \mathrm{kN}$, respectively. Before reaching the critical values, the full-section of the beam is under compression; then, the lowermost laminate is under tension. By comparing the critical value of the load of the fifth-layer laminate and its failure load, the test beams SPF-1.1, SPF-1.2, and SPF-1.3 are subjected to tension when reaching the corresponding ultimate loads of $8.55 \%, 7.08 \%$, and $7.07 \%$, respectively. This result indicates that, at the initial loading stage, the influence of the end arm on the stiffness of the beam is negligible, while at the later stage of loading, with the increase of the stress of the steel wire, the bending moment of the beam-end is also increased, thereby improving the bearing capacity of the beam.

3.5. Verification of Plane Cross Section Assumption. To verify the plane cross section assumption of the prestressed glulam beam, the section-strain relationship curve of the beam under various grades of loads is plotted, as shown in Figures 12 and 13. In the figures, the $X$-axis denotes the actual strain value of each laminate, the negative value represents compression, and the positive value represents tension. The $Y$-axis is the centroid position of the strain gauge of each laminate: $2.5 \mathrm{~mm}, 25 \mathrm{~mm}, 50 \mathrm{~mm}, 75 \mathrm{~mm}$, and $97.5 \mathrm{~mm}$ from the bottom of the beam.

Thus, during the initial loading stage, the position of the neutral axis moves down slightly. During the last stage of loading, the ordinate of the position of the neutral axis reaches the minimum value due to the stress redistribution between the beam and the steel wire. The comparison of the section-strain curves of beams in group A shows the following: (1) The failure modes of both SPF-1.1 and SPF-1.2 are brittle tension failures; that is, the tensile strength of the bottom of the beam is reached during failure, while the compressive strength of the top of the beam is not reached. The strain curve of SPF-1.1 and SPF-1.2 is consistent with the plane section assumption. (2) A vertical part appears in the upper section-strain curve of SPF-1.3 that is, the beam top reaches the compressive strength and has a certain plastic region. The beam conforms to the plane section assumption in the elastic stage, while in the later stage when the 


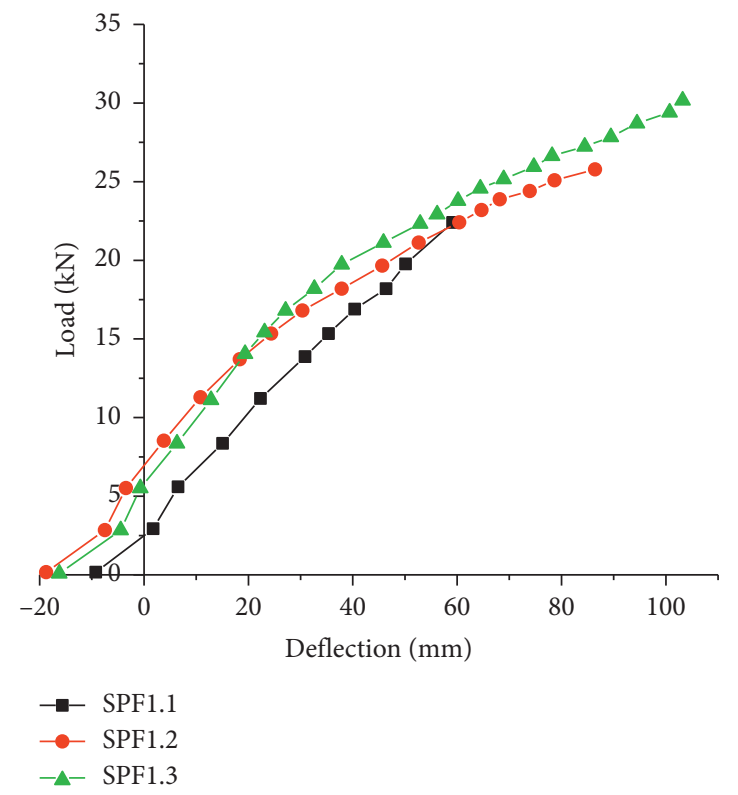

FIgUre 6: Load-deflection curve of test beams in group A.

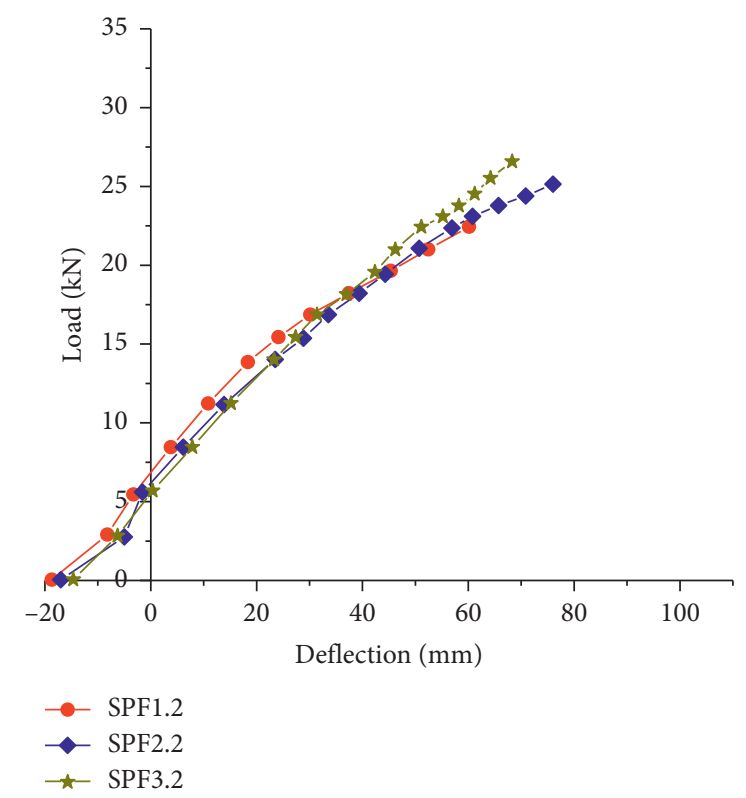

Figure 7: Load-deflection curve of test beams in group B.

compression zone of the beam top becomes plastic, the beam no longer meets the plane section assumption. (3) By comparing the section-strain curves of the three beams under their own maximum load, we found that as the height of string arm increases, the neutral axis moves downward; this outcome agrees with the failure mode.

As can be seen from Figure 13, the position of the neutral axis would move slightly at the initial stage of loading. At the last stage of loading, the position of the neutral axis reaches the lowest value on the ordinate because of the stress redistribution between the glued laminated timber and the steel wire. The comparison of cross section-strain curves of beams with different end arms in group B shows the following: (1) Since SPF-1.2 is subjected to brittle tensile failure, that is, the bottom of the beam reaches tensile strength while the top of the beam does not reach compressive strength, the strain curve conforms to the plane cross section assumption. (2) The slopes of SPF-2.2 and SPF-3.2 cross section-strain curves increase; that is, the top of the beam has a plastic region. (3) By comparing the cross-sectional strain curves of 

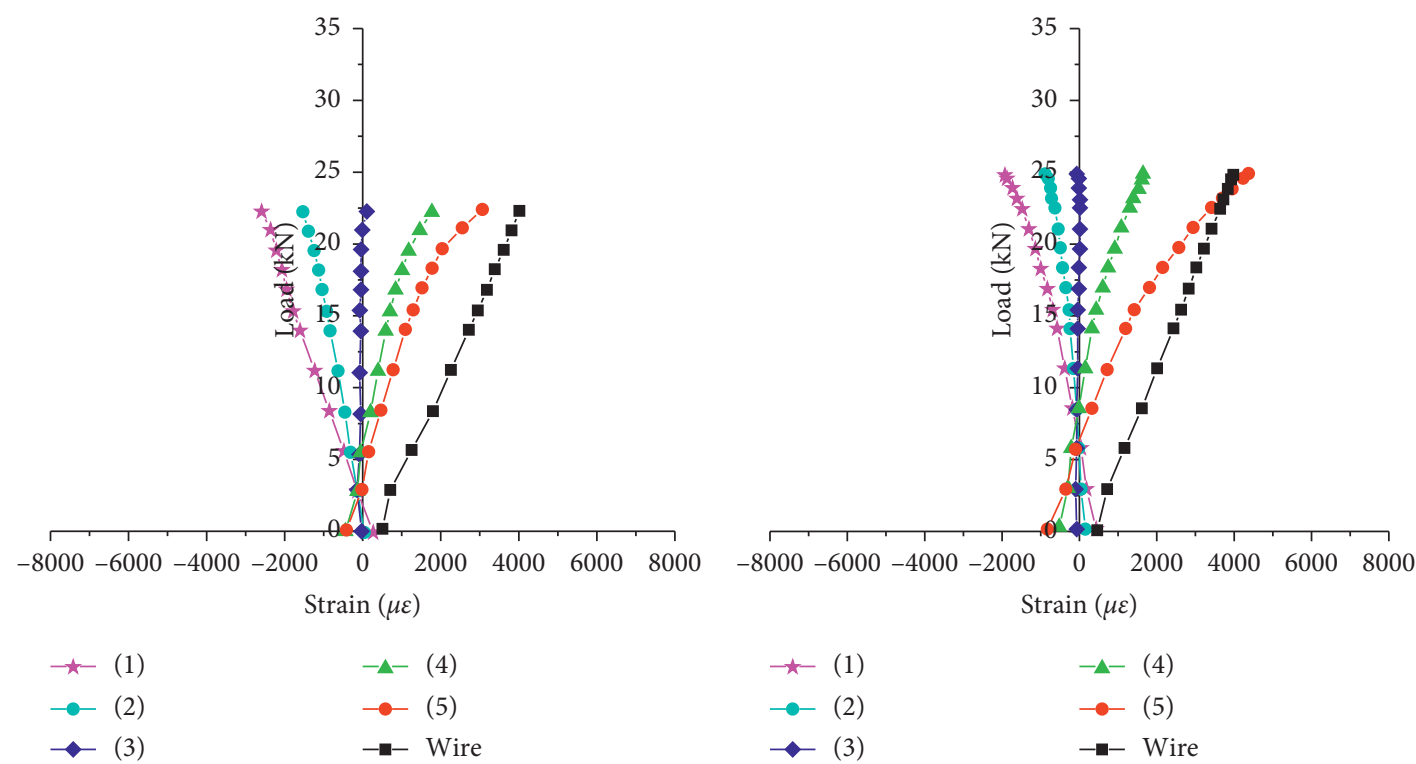

(a)

(b)

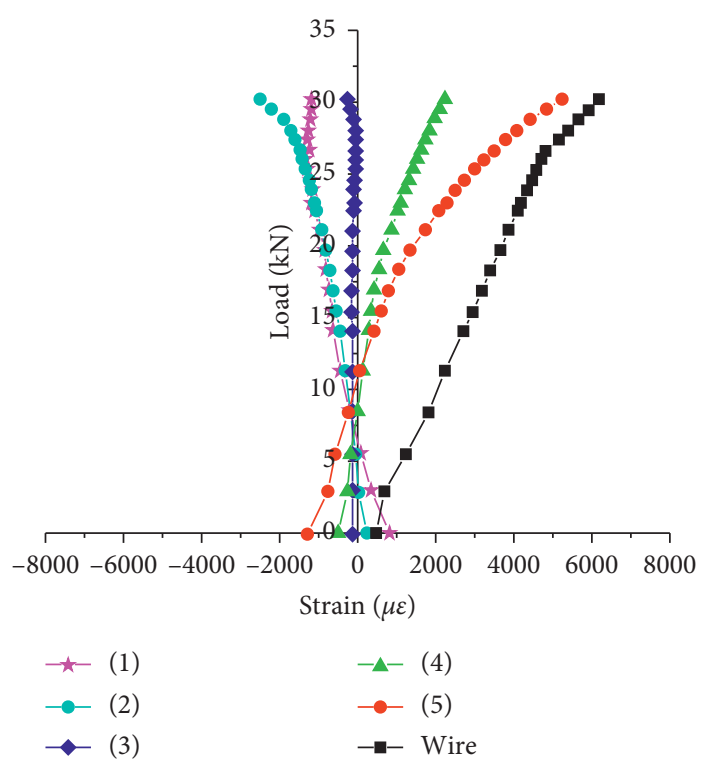

(c)

Figure 8: Load-strain relationship curve in group A. (a) SPF-1.1. (b) SPF-1.2. (c) SPF-1.3.

the three beams under their own maximum load, the neutralization axis moves downward with the increase of the force arm at the end.

\section{Theoretical Analysis}

4.1. Failure Type. Before deducing the formula, it is necessary to define the failure mode of the glulam beam and give the corresponding calculation formula for each failure type. With reference to relevant materials [22] and the completed flexural test of prestressed glulam beams, the failure types of glulam beams with reinforcement are classified as follows.
4.1.1. Failure Type No. 1. When the beam is subjected to a large load, the height of the compression zone of the glued laminated timber increases. The wood in the tension zone first reaches the tensile strength and breaks. At this time, due to the existence of steel wire, the neutral axis moves down. Although the glued laminated timber shows no significant change at the top, it reaches compressive strength. This is brittle tension failure.

4.1.2. Failure Type No. 2. Under a large load, the glulam beam shows significant plastic deformation in the compression zone, and the steel bars in the tension zone do not 


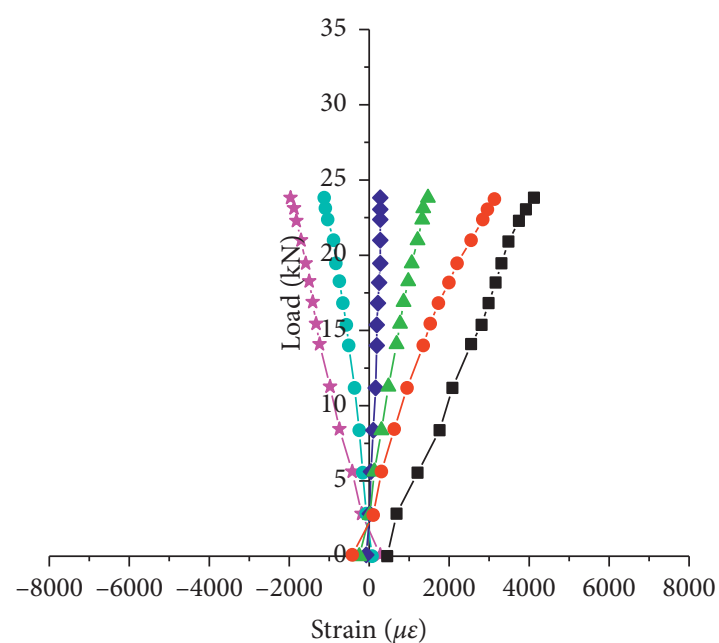

Strain $(\mu \varepsilon)$

$\begin{array}{ll}\rightarrow-(1) & -\Delta(4) \\ \rightarrow-(2) & -\bullet(5) \\ \bullet(3) & -\square \text { Wire }\end{array}$

(a)
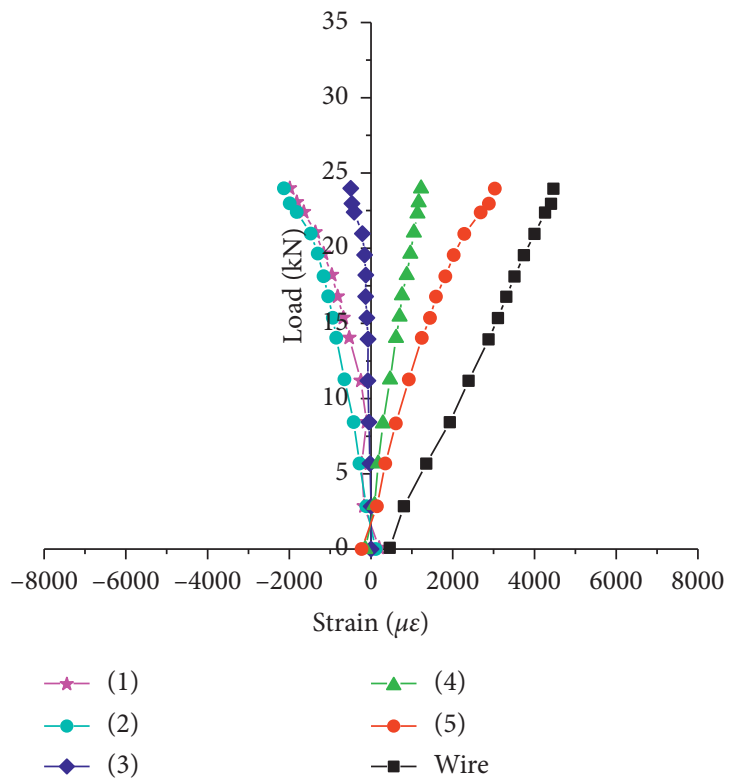

(b)

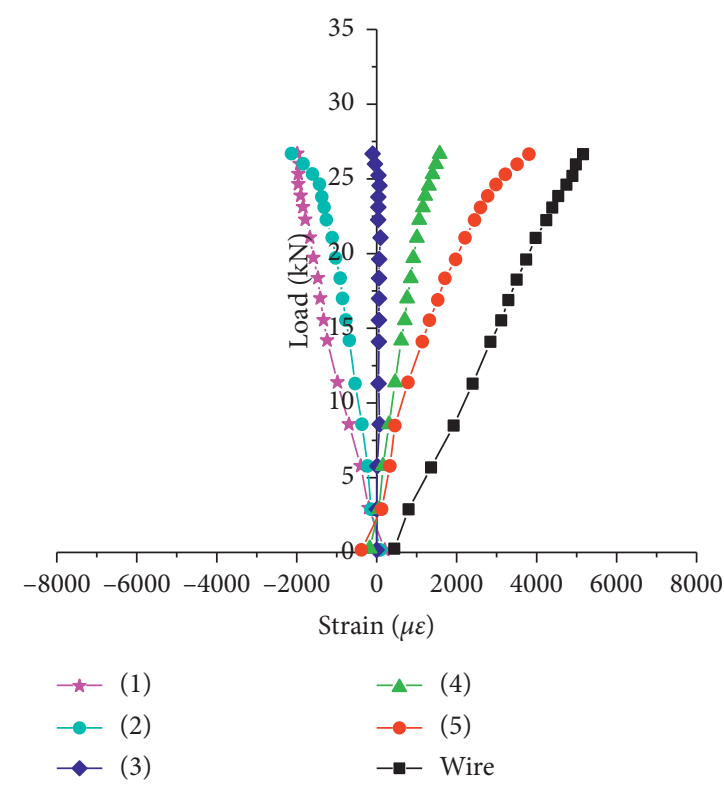

(c)

FIGURE 9: Load-strain relationship curve in group B. (a) SPF1.2. (b) SPF2.2. (c) SPF3.2.

yield. However, the wood fiber in the tension zone reaches the ultimate tensile strain and breaks. This is a type of ductile tension failure. The tension failure of glued laminated timber bottom caused by end fracture is also a type of ductile tension failure because, during stress redistribution, the top of the glued laminated timber, too, reaches its compressive strength.

In this experiment, the relationship between the failure modes of glulam beams and the corresponding failure types is shown in Table 3.

Based on these two failure types, the corresponding bearing capacity formula is derived as follows.
4.2. Fundamental Assumption. To obtain the bearing capacity formula, the following basic assumptions should be adopted:

(1) When the prestressed glulam beam is flexural, it meets the plane cross section assumption.

(2) The elastic modulus obtained from the compression test of the wood prism is taken as the elastic modulus for the glued laminated timber.

(3) The stress-strain relationship of glulam beams under bending is similar to that in Figure 14. 


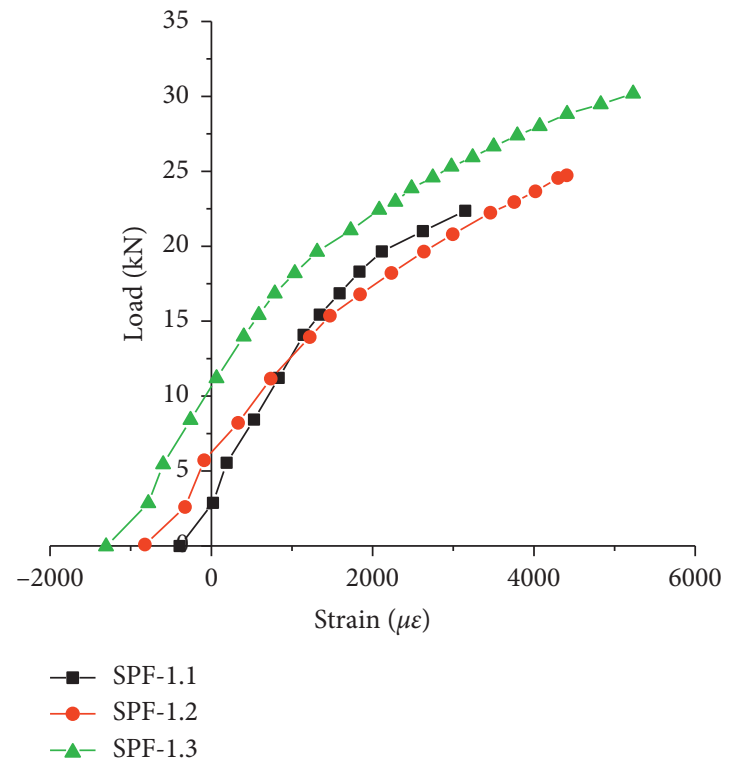

FIGURE 10: Load-strain curve of the fifth-layer laminate of the test beam in group A.

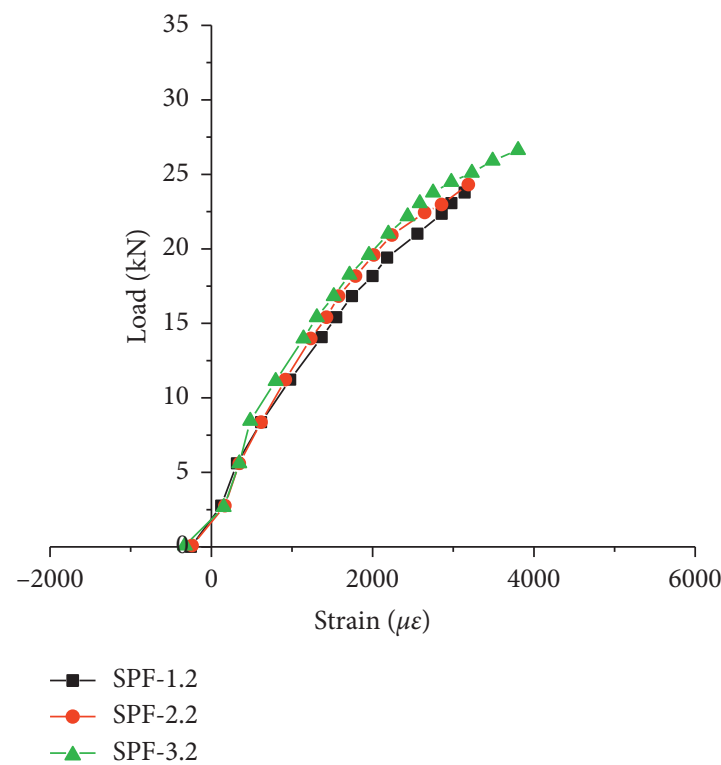

Figure 11: Load-strain curve of the fifth-layer laminate of the test beam in group B.

(4) When the prestressed glulam beam proposed in this paper is damaged, the glued laminated timber at the bottom (and top) of the beam fails to reach its tensile (compressive) strength.

4.3. Formula Derivation. Based on the above assumptions, the calculation diagram of the failure of prestressed glulam beams is shown in Figure 15.

As shown in Figure 15, $h$ is the beam height, $b$ is the beam width, and $z$ is the distance from the steel wire to the bottom of the glued laminated timber. When the glulam beam is damaged by tension, the height of the compression zone is $x$. The previous analysis shows that, regardless of which type of failure happens, the deformation of the wood fiber at the beam top reaches the yield strain values but does not exceed the ultimate strain value; that is, $\varepsilon_{\mathrm{cu}}>\varepsilon_{\mathrm{c}}>\varepsilon_{\mathrm{cy}}$. According to the stress of the glued laminated timber shown in Figure 15, the compressive stress at this time no longer increases with the increase of compressive strain, forming a plastic region with a height of $m$ and stress of $\sigma_{\mathrm{c}}=f_{\mathrm{cu}}$. At the same time, the prestressed steel wire does not yield, and the stress $\sigma_{\mathrm{r}}$ increases with the increase of $\varepsilon_{\mathrm{r}}$. However, the fiber at the bottom of the glued laminated timber reaches the ultimate strain value, $\varepsilon=\varepsilon_{\mathrm{tu}}$, and the tensile stress also reaches the ultimate value, $\sigma_{\mathrm{t}}=f_{\mathrm{tu}}$. 


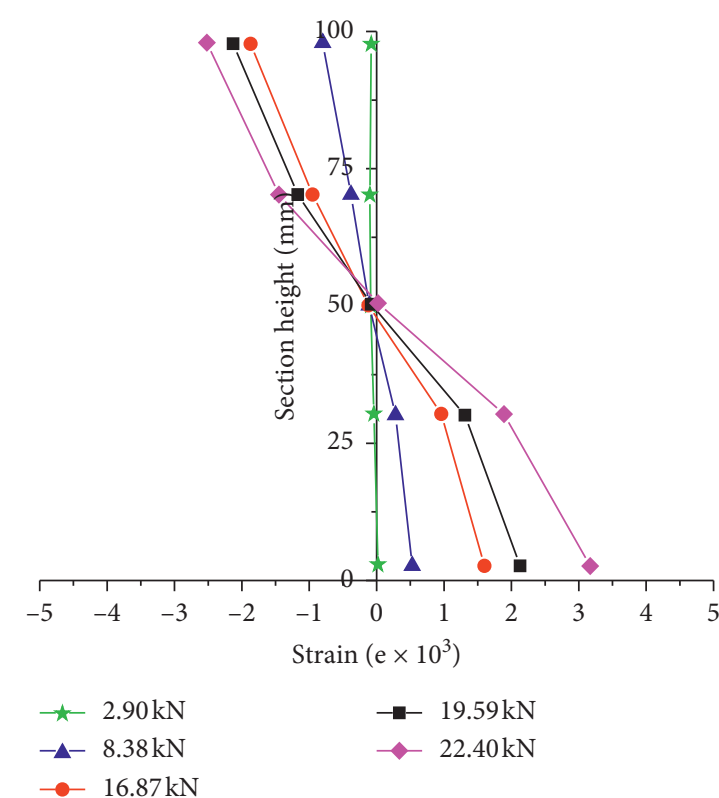

(a)

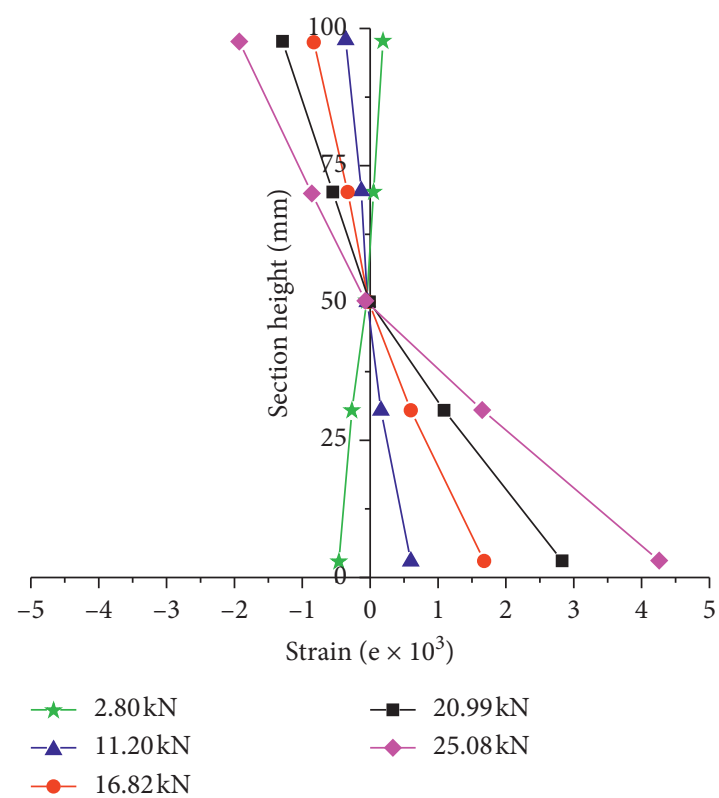

(b)

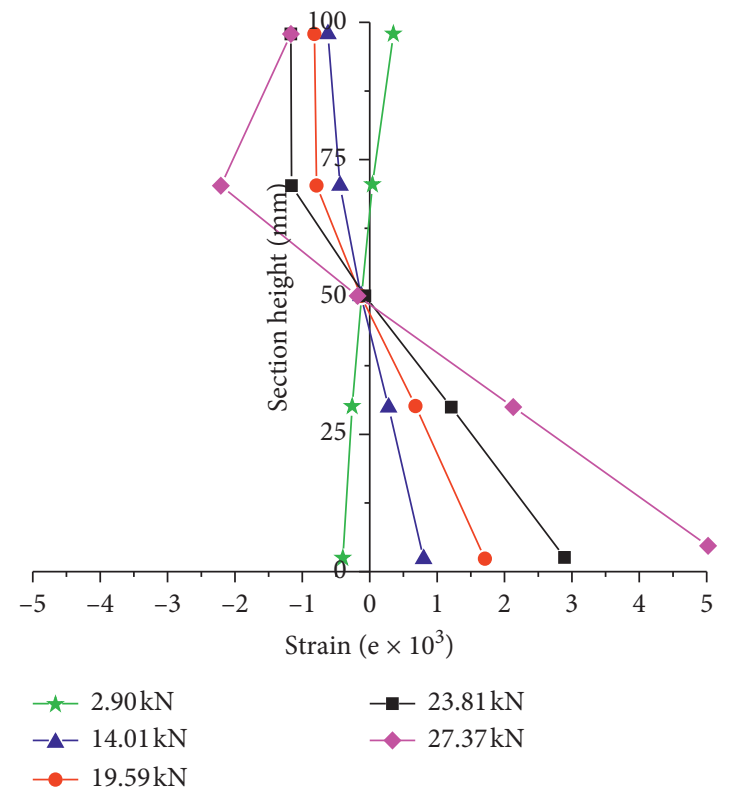

(c)

Figure 12: Section-strain curve of test beams in group A. (a) SPF-1.1. (b) SPF-1.2. (c) SPF-1.3.

According to the section-stress relationship in Figure 15, the equilibrium equations of force and bending moment can be obtained when the glued wood beam is stressed, as shown below:

Force equilibrium:

$$
\sigma_{c} m b+\frac{1}{2} \sigma_{c} \times(x-m) \times b=\sigma_{r} A_{s}+\frac{1}{2} \sigma_{t} \times(h-x) \times b .
$$

$$
\begin{aligned}
M & =M_{1}+M_{2}, \\
M_{1} & =\sigma_{c} m b \times\left(h+z-\frac{m}{2}\right)+\frac{1}{2} \sigma_{c} \times(x-m) \times b \\
& \times\left(h+z-m-\frac{x-m}{3}\right)-\frac{1}{2} \sigma_{t} \times(h-x) \times b \\
& \times\left(z+\frac{h-x}{3}\right),
\end{aligned}
$$

Bending moment equilibrium:

$$
M_{2}=F \times y,
$$




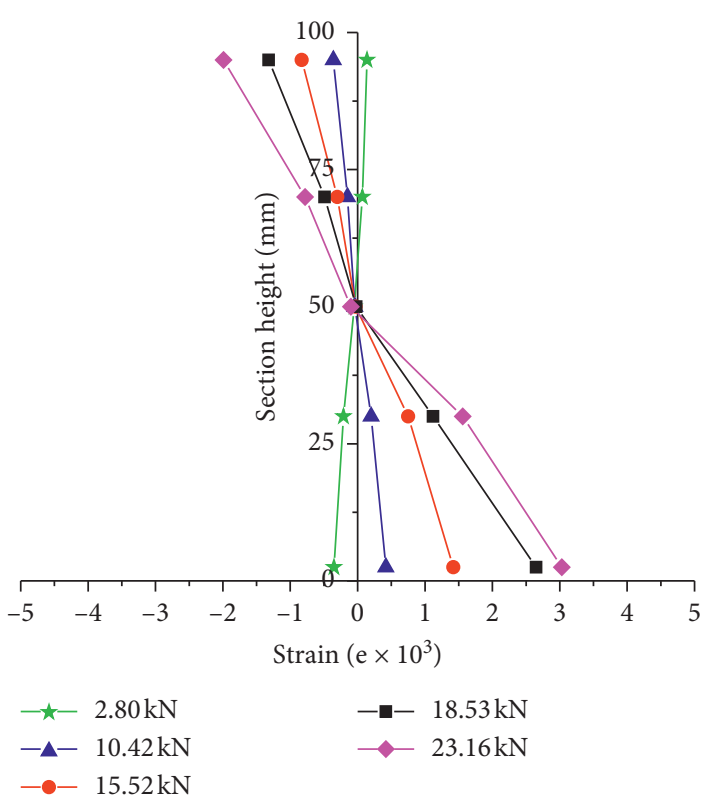

(a)

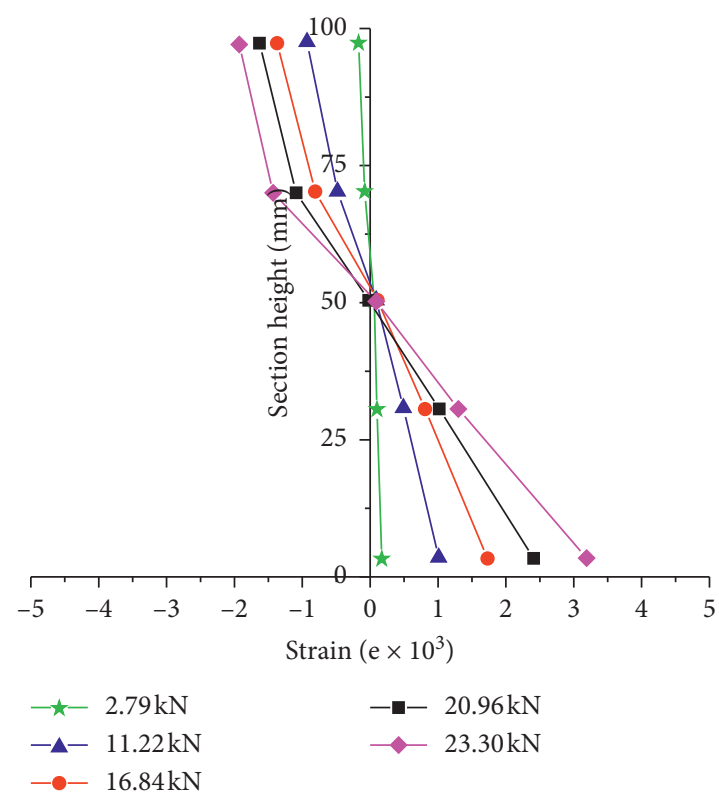

(b)

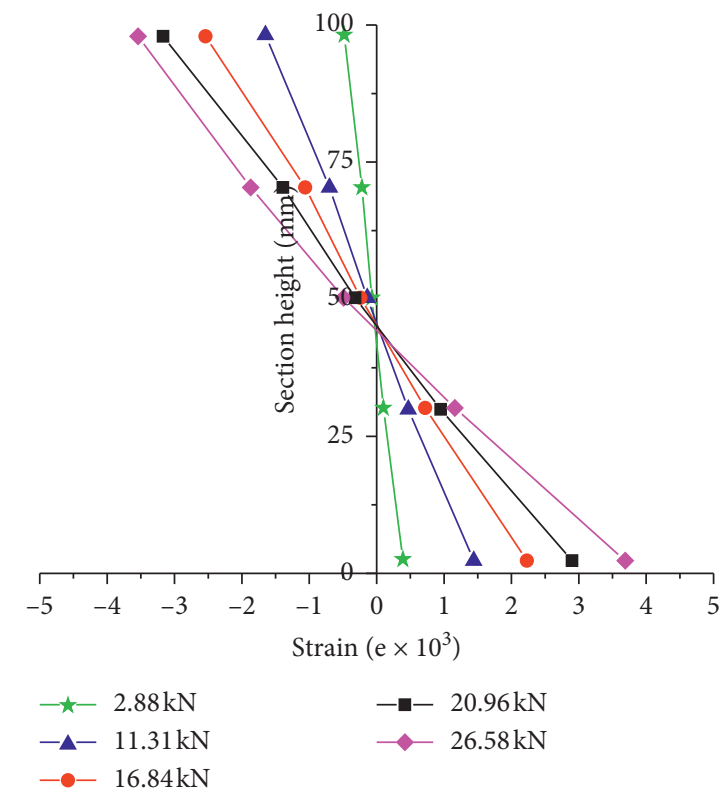

(c)

Figure 13: Section-strain curve of test beams in group B. (a) SPF-1.2. (b) SPF-2.2. (c) SPF-3.2.

where $h$ is the height of the glulam beam; $b$ is the width of the glulam beam; $z$ is the distance from the steel wire to the glulam beam bottom; $x$ is the height of the compression zone of the glued laminated timber; $m$ is the height of the plastic area of the glued laminated timber; $\sigma_{c}$ is the compressive strain at the top of the glulam beam; $\sigma_{t}$ is the tensile strain at the bottom of the glulam beam; $\sigma_{r}$ is the tensile strain of the steel wire; $A_{s}$ is the reinforcement area of the prestressed steel wire; $M$ is the design value for the bending moment of the cross section of the glulam beam; $M_{1}$ is the bending moment generated by the glulam beam and steel wire; $M_{2}$ is the bending moment generated when the prestress at the steel wire end shifts to the beam centroid during prestressing; $F$ is prestress, which is $3.8 \mathrm{kN}$ in the test; and $y$ is the distance from the anchoring position of the steel wire end to the beam centroid. According to (1), two unknowns in the equation, $m$ and $x$, can only be solved by the triangle similarity theorem: $\sigma_{t} / \sigma_{c}=(h-x) /(x-m)$. 
TABLE 3: Relationship between the failure modes of test beams and the corresponding failure types.

\begin{tabular}{|c|c|c|c|}
\hline Group & Beam no. & Failure mode & Failure type \\
\hline \multirow{3}{*}{ SPF-1.1 } & SPF-1.1 (1) & Steel bar defect & Type No. 1 \\
\hline & SPF-1.1 (2) & The lowermost laminate breaks & \multirow[b]{2}{*}{ Brittle tension failure } \\
\hline & SPF-1.1 (3) & The lowermost laminate breaks & \\
\hline \multirow{3}{*}{ SPF-1.2 } & SPF-1.2 (1) & - & Type No. 1 \\
\hline & SPF-1.2 (2) & Tension failure of the beam bottom & \multirow{2}{*}{ Brittle tension failure } \\
\hline & SPF-1.2(3) & Tension failure of the beam bottom & \\
\hline \multirow{3}{*}{ SPF-1.3 } & SPF-1.3 (1) & - & Type No. 2 \\
\hline & SPF-1.3 (2) & Compression failure of the beam top & \multirow{2}{*}{ Ductile tension failure } \\
\hline & SPF-1.3 (3) & Ductile tension of the beam bottom & \\
\hline \multirow{3}{*}{ SPF-2.2 } & SPF-2.2 (1) & - & Type No. 1 \\
\hline & SPF-2.2 (2) & Tension failure of the beam bottom & \multirow{2}{*}{ Brittle tension failure } \\
\hline & SPF-2.2(3) & Tension failure of the beam bottom & \\
\hline \multirow{3}{*}{ SPF-3.2 } & SPF-3.2 (1) & Breakage of the beam-end & Type No. 2 \\
\hline & SPF-3.2 (2) & Tension failure of the beam bottom due to the beam-end breakage & \multirow{2}{*}{ Ductile tension failure } \\
\hline & SPF-3.2 (3) & Tension failure of the beam bottom due to the beam-end breakage & \\
\hline
\end{tabular}

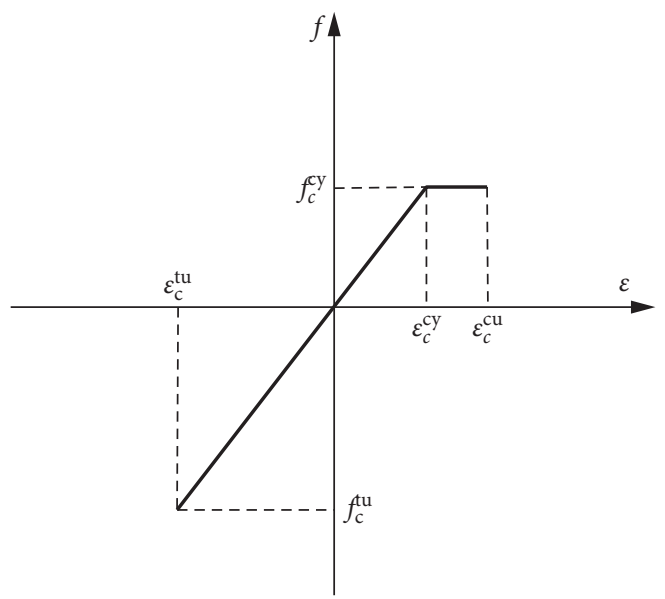

FIGURE 14: Constitutive model of the stress-strain relationship of the glulam beam.

Based on this formula, the calculation results of each group of glulam beams are verified, as shown in Table 4.

In this test, the cross section size of the glulam beam is $b=h=100 \mathrm{~mm}$, and the reinforcement is composed of 2 round prestressed steel wires with a diameter of $7 \mathrm{~mm}$. Based on the compression test results of the wood prism and the tension test of the wood component, the compressive strength, tensile strength, and elastic modulus of this batch of SPF are $32.2 \mathrm{~N} / \mathrm{mm}^{2}, 78.2 \mathrm{~N} / \mathrm{mm}^{2}$, and $10350.2 \mathrm{~N} / \mathrm{mm}^{2}$, respectively. However, the tensile strength obtained here is not the actual tensile strength but the data obtained from the tensile strength standard. In the test of the standard tensile component, the observed part is the part along the grain without the influence of knot, which is different from the stress of glulam beams in the actual situation. Therefore, it is necessary to consider the factors that affect the resistance of the components and calibrate the reliability of the tensile strength of the glulam beams. The formula is as follows:

$$
f_{\mathrm{Q}}=K_{\mathrm{Q}} f \text {, }
$$

where $f_{Q}$ is the material strength of the component; $K_{Q}$ is coefficient conserving the influence factors; and $f$ is the material strength of the specimen, i.e., standard tensile component.

The value of $K_{Q}$ is determined by many factors. The Wood Construction Design Manual [23] mainly introduces four most common factors, namely, the knot with natural defect and twill $\left(K_{Q 1}\right)$, timber cracks due to the decrease in the moisture content $\left(K_{Q 2}\right)$, influence of timber creep due to long-term use on the component strength $\left(K_{Q 3}\right)$, and size effects $\left(K_{Q 4}\right)$.

$$
K_{\mathrm{Q}}=K_{\mathrm{Q} 1} \times K_{\mathrm{Q} 2} \times K_{\mathrm{Q} 3} \times K_{\mathrm{Q} 4},
$$

The value of $K_{Q 1}$ is determined based on the statistical parameter and specific test phenomenon given in Table 3.2.3 of Wood Construction Design Manual [23]; i.e., $K_{Q 1}=0.6$. The value of $K_{Q 2}$ can be obtained from the formula for calculating the tensile strength along the grain of bending composite timber according to the structural glued laminated timber (GBT 26899-2011); i.e., $K_{Q 2}=0.9997$. The influence coefficients of creep and size effect can be referred to as the statistical coefficients in the Wood Construction Design Manual; $K_{Q 3}=0.72$ and $K_{Q 4}=0.89$. $K_{Q}=$ $K_{Q 1} \times K_{Q 2} \times K_{Q 3} \times K_{Q 4}=0.6 \times 0.9997 \times 0.72 \times 0.89=0.38$. 


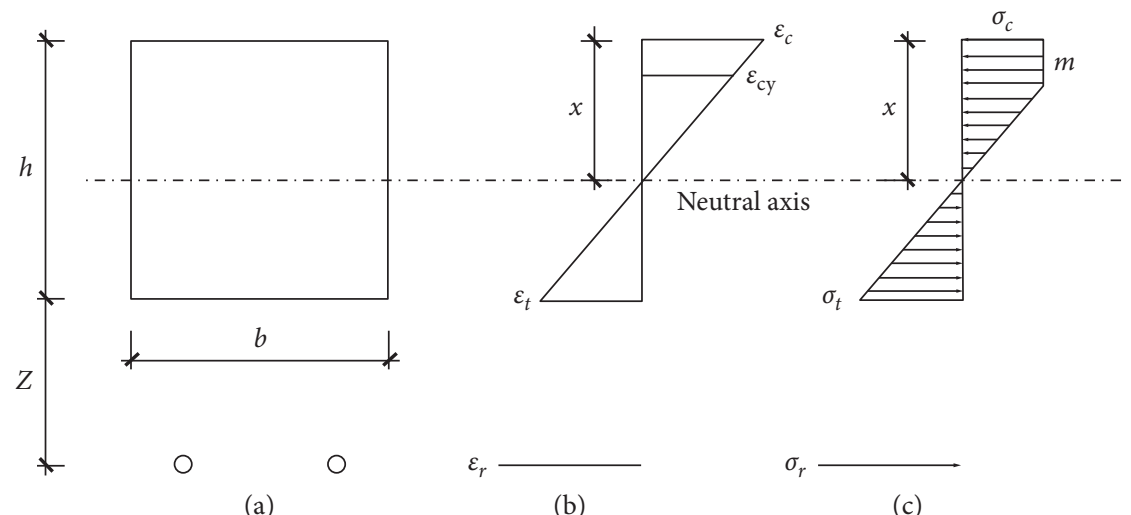

Figure 15: Calculation diagram of the failure of the prestressed glulam beam. (a) Computing model. (b) Strain diagram. (c) Stress diagram.

TABle 4: Comparison of the calculation value and the test value of the flexural bearing capacity.

\begin{tabular}{|c|c|c|c|c|c|c|c|c|c|c|}
\hline \multirow[t]{2}{*}{ Group } & \multirow[t]{2}{*}{$f_{y}\left(\mathrm{~N} / \mathrm{mm}^{2}\right)$} & \multirow[t]{2}{*}{$X(\mathrm{~mm})$} & \multirow[t]{2}{*}{$M(\mathrm{~mm})$} & \multirow[t]{2}{*}{$Z(\mathrm{~mm})$} & \multirow[t]{2}{*}{$M_{1}(\mathrm{kN} \cdot \mathrm{m})$} & \multirow[t]{2}{*}{$Y(\mathrm{~mm})$} & \multirow[t]{2}{*}{$M_{2}(\mathrm{kN} \cdot \mathrm{m})$} & \multicolumn{2}{|c|}{$\begin{array}{l}\text { Bending moment of } \\
\text { midspan }(\mathrm{kN} \cdot \mathrm{m})\end{array}$} & \multirow[t]{2}{*}{ Error \% } \\
\hline & & & & & & & & Calculation & Test & \\
\hline SPF-1.1 & 350.00 & 57.00 & 10.41 & 90.00 & 11.87 & 60 & 0.228 & 12.10 & 11.30 & 6.62 \\
\hline SPF-1.2 & 400.00 & 57.63 & 11.71 & 130.00 & 14.43 & 60 & 0.228 & 14.66 & 12.06 & 17.73 \\
\hline SPF-1.3 & 450.00 & 58.25 & 13.02 & 170.00 & 17.31 & 60 & 0.228 & 17.54 & 13.24 & 24.51 \\
\hline SPF-2.2 & 400.00 & 57.63 & 11.71 & 130.00 & 14.43 & 80 & 0.304 & 14.74 & 12.58 & 14.63 \\
\hline SPF-3.2 & 400.00 & 57.63 & 11.71 & 130.00 & 14.43 & 100 & 0.380 & 14.81 & 13.04 & 11.96 \\
\hline
\end{tabular}

Therefore, $K_{Q}=0.38$ and the tensile strength $\sigma t$ is $29.7 \mathrm{~N} /$ $\mathrm{mm}^{2}$.

Comparing the calculation value in Table 4 with the test value, we find that the error ranges from $6.62 \%$ to $24.51 \%$. Considering the high dispersion of the strength of the glued laminated timber, the bearing capacity calculation formula can better reflect the actual stress on the glulam beam, indicating that the derivation of the calculation formula is reasonable and accurate.

\section{Conclusions}

(1) When the height of the end arm is constant and the string arm increases from $90 \mathrm{~mm}$ to $130 \mathrm{~mm}$ and $170 \mathrm{~mm}$, the bearing capacity of the beam increases by $6.77 \%$ and $17.22 \%$, respectively. At the same time, the height of the compression zone of glued laminated timber increases gradually, the failure mode of the beam is gradually transferred from brittle tension failure of the beam bottom to ductile compression failure of the beam top, and the deformation capacity of the beam is also greatly improved.

(2) When the height of the string arm is constant and the end arm increases from $10 \mathrm{~mm}$ to $30 \mathrm{~mm}$ and $50 \mathrm{~mm}$, the bearing capacity of the beam increases by $4.27 \%$ and $8.13 \%$, respectively. Although the beam has no significant change in the failure mode, it can be fully used to bear the stress more uniformly. However, the increase in the height of the end arm should be controlled reasonably to avoid the beamend breakage caused by the excessive end arm.
(3) The failure section of the test beam meets the plane section assumption. Based on the principles of equilibrium, moment equilibrium, and similar triangle, the formula to calculate the ultimate bearing capacity of the glulam beam is deduced with a calculation error within $6.62 \%-24.51 \%$.

\section{Data Availability}

The data used to support the findings of this study are included within the article.

\section{Conflicts of Interest}

The authors declare that they have no conflicts of interest regarding the publication of this paper.

\section{Acknowledgments}

This project was supported by the Fundamental Research Funds for the Central Universities (grant no. 2572017DB02), the Natural Science Foundation of Heilongjiang Province (grant nos. LH2019E005 and LH2020E009), and the Harbin Science and Technology Innovation Talent Fund Project (grant no. 2017RAQXJ086).

\section{References}

[1] I. Bejtka, Cross (CLT) and Diagonal (DLT) Laminated Timber as Innovative Ma-Terial for Beam Elements, Karlsruhe Institute of Technology, Karlsruhe, Germany, 2011. 
[2] P. Crespell and S. Gagnon, Cross Laminated Timber: A Primer, Fpinnovations, Vancouver, QC, Canada, 2010.

[3] P. Gilham, "AN overview of fire resistive design of exposed timber structures," World Architecture, vol. 9, 2002.

[4] H. Zhang, H. Li, I. Corbi et al., "AFRP influence on parallel bamboo strand lumber beams," Sensors, vol. 18, no. 9, p. 2854, 2018.

[5] H.-t. Li, J.-w. Su, A. J. Deeks, Q.-s. Zhang, D.-d. Wei, and C.-g. Yuan, "Eccentric compression performance of parallel bamboo strand lumber columns," BioResources, vol. 10, pp. 7065-7080, 2015.

[6] R. Tomasi, M. A. Parisi, and M. Piazza, "Ductile design of glued-laminated timber beams," Practice Periodical on Structural Design and Construction, vol. 14, no. 3, pp. 113-122, 2009.

[7] A. H. Buchanan, "Bending strength of lumber," Journal of Structural Engineering, vol. 116, no. 5, pp. 1213-1229, 1990.

[8] G. P. Gardner and R. D. Eaton, "Reinforced laminated timber: google patents," 1991.

[9] M. E. O’brien, "Reinforced laminated beam: google patents," 1991.

[10] T. C. Triantafillou and N. Deskovic, "Prestressed FRP sheets as external reinforcement of wood members," Journal of Structural Engineering, vol. 118, no. 5, pp. 1270-1284, 1992.

[11] N. Khorsandnia, H. R. Valipour, and K. Crews, "Nonlinear finite element analysis of timber beams and joints using the layered approach and hypoelastic constitutive law," Engineering Structures, vol. 46, pp. 606-614, 2013.

[12] M. M. Hassani, F. K. Wittel, S. Hering, and H. J. Herrmann, "Rheological model for wood," Computer Methods in Applied Mechanics and Engineering, vol. 283, pp. 1032-1060, 2015.

[13] N. Guo, Y. Zuo, and H. L. Zuo, "Bending performance of gluelumber beam reinforced by bamboo plyboard," Journal of Jilin University, Engineering and Technology Edition, vol. 47, pp. 778-788, 2017.

[14] G. Nan, W. Yan-Jun, and Z. Hong-Liang, "Study of shortterm flexural behavior for glue-bamboo and lumber beams under different pre-stressed states," Civil Engineering Journal, vol. 2, pp. 128-142, 2017.

[15] V. De Luca and C. Marano, "Prestressed glulam timbers reinforced with steel bars," Construction and Building $\mathrm{Ma}$ terials, vol. 30, pp. 206-217, 2012.

[16] H. Yang, D. Ju, W. Liu, and W. Lu, "Prestressed glulam beams reinforced with CFRP bars," Construction and Building Materials, vol. 109, pp. 73-83, 2016.

[17] J. Zhang, H. Shen, R. Qiu et al., "Short-term flexural behavior of prestressed glulam beams reinforced with curved tendons," Journal of Structural Engineering, vol. 146, no. 6, Article ID 04020086, 2020.

[18] S. Masao, O. Akira, M. Katsuo, and G. Tetsuo, "Study on mechanical characteristics of a light-weight complex structure composed of a membrane and a beam string structure," in proceedings of the IASS-ASCE International Symposium on Spatial, Lattice and Tension Structures, pp. 632-641, Congress, Atlanta, GA, April 1994.

[19] C. Q. Gui, W. J. G., M. Yang, "Analysis on the influencing factors of the flexural behaviors of ECC-C composite beams," Jiangsu Construction, vol. 11, 14 pages, 2016.

[20] H. Peng, J. R. Z., H. X. Hao, "Experimental research on mechanicalbehavior of RC flexural members with corroded plainsteel bars," Journal of Highway and Transportation.

[21] J. Y. Li, Y. Q. Hu, Xu Gao et al., "Analysis of the influence of internal force arm on the bending performance of glulam beams," Shanxi Architecture, vol. 42, no. 14, pp. 39-40, 2016.
[22] F. Li, Research on the Bend Resistance of the FRP Reinforced Timber Beam. Master Thesis, Huaqiao University, Quanzhou, China, 2009.

[23] E. Manual, Wood Construction Design Manual, China Architecture and Building Press, Beijing, China, 2005. 